\section{Chemical Fluid Deposition Enables Conformal Coating of High- Aspect-Ratio Features in Si Wafers}

The increasing miniaturization of microelectronic devices has put heavy demands on the technologies used to produce them. For example, as the width of interconnect features in integrated circuits approaches $100 \mathrm{~nm}$, conventional deposition techniques may be insufficient to uniformly fill these high-aspect-ratio channels with copper. Current $\mathrm{Cu}$ metallization techniques based on electrolytic plating require a conformal seed layer prior to feature fill. These seed layers are deposited using lineof-sight physical vapor deposition techniques that become limited in small, highaspect-ratio features. An alternative is to use chemical vapor deposition (CVD). The relatively low vapor pressures of the organometallic precursors used in CVD, however, produce mass-transport limitations that can lead to nonuniform deposition of metal in the channels, resulting in faulty connections between functional devices on a chip.

To overcome these limitations, researchers at the University of Massachusetts have developed a technique called chemical fluid deposition (CFD), which involves organometallic precursors dissolved in supercritical $\mathrm{CO}_{2}\left(\mathrm{sc}-\mathrm{CO}_{2}\right)$. As reported by J. Blackburn and co-workers in the October 5 issue of Science, CFD provides a precursor concentration of up to 3 orders of magnitude greater than CVD, while maintaining transport properties that are similar to those of a gas; this combination allows rapid diffusion of the organometallic into the narrow channels, promoting a uniform conformal coating. The addition of hydrogen gas, which is miscible in $\mathrm{sc}-\mathrm{CO}_{2}$, then reduces the precursor to its metallic state, the researchers said.

Silicon test wafers were placed in a coldwalled high-pressure reactor vessel at a pressure of $200 \mathrm{~atm}$. The silicon substrate was resistively heated to temperatures ranging from $175^{\circ} \mathrm{C}$ to $200^{\circ} \mathrm{C}$ in sc- $\mathrm{CO}_{2}$ solutions containing $\mathrm{Cu}(\mathrm{II})$ bishexafluoroacetylacetonate $\left[\mathrm{Cu}(\mathrm{hfac})_{2}\right]$ or $\mathrm{Cu}(\mathrm{II})$ tetramethylheptanedionate [Cu(tmhd $)_{2}$ ]. Copper was deposited by hydrogen reduction exclusively on $\mathrm{Ni}$ films or small $\mathrm{Pd}$ seed clusters. By raising the temperature to $250^{\circ} \mathrm{C}$, the researchers were able to deposit metallic $\mathrm{Cu}$ from $\mathrm{Cu}(\mathrm{tmhd})_{2}$ directly onto the native silicon oxide surface in a single step, without the need for seed crystals. $\mathrm{Cu}(\mathrm{tmhd})_{2}$ provides the option of a nonfluorinated precursor, which reduces environmental concerns, according to the research team. The deposited films were continuous, highly reflective, and essentially free of impurities.
The researchers also deposited nickel onto Pd seed clusters from a solution of bis(cyclopentadienyl)nickel $\left(\mathrm{NiCp}_{2}\right)$ in sc$\mathrm{CO}_{2}$ in a hot-walled reactor at $60^{\circ} \mathrm{C}$ and $200 \mathrm{~atm}$ in the presence of hydrogen. They said that raising the temperature to $120^{\circ} \mathrm{C}$ eliminated the need for seed clusters.

For both $\mathrm{Cu}$ and $\mathrm{Ni}$, scanning electron microscopy images revealed conformal coating of 100-nm-wide by 800 -nm-deep channels etched in silicon wafers, the researchers said. Furthermore, they said, secondary-ion mass spectrometry analysis showed the deposited films to be sufficiently pure, and resistivity measurements were well within specifications for $\mathrm{Cu}$ interconnect structures.

Tim PALUCKA

\section{Antireflection Microstructures Achieved with $\mathrm{F}_{2}$-Doped $\mathrm{SiO}_{2}$ Films}

Sub-wavelength-structured (SWS) surfaces with surface-relief gratings with a period smaller than the wavelength of light have received increased interest for their potential in applications such as waveguides, optical fibers, and electrooptical materials. Among the SWS surfaces, antireflective coatings are generally obtained in glass by treating the surface with acid, a process that leads to a gradual change in the refractive index and a measurable decrease of reflection at the surface, equivalent to that of a multilayered antireflective coating. In the November 1 issue of Optics Letters, a team of researchers in Japan from the National Institute of Advanced Industrial Science and Technology, Osaka Prefecture University, and Samco International reported on their fabrication technique for SWS surfaces, which uses a fluorine-doped $\mathrm{SiO}_{2}$ film.

The researchers obtained fluorine-doped $\mathrm{SiO}_{2}$ by a plasma-enhanced chemical vapor deposition system with $\mathrm{Si}\left(\mathrm{OC}_{2} \mathrm{H}_{5}\right)_{4}$ and $\mathrm{CF}_{4}$ as raw materials. They controlled the content of the fluorine in the film by controlling the flow rate of the $\mathrm{CF}_{4}$. After deposition, the films were etched in a 5\%diluted $\mathrm{HF}$ solution at $25^{\circ} \mathrm{C}$. To obtain the two-dimensional (2D) periodic antireflective structures, a six-layer film of $\mathrm{F}_{2}$-doped $\mathrm{SiO}_{2}$ was deposited on a $\mathrm{SiO}_{2}$ substrate. Each layer was $0.2 \mu \mathrm{m}$, and the content of $F_{2}$ was varied at $0,6,7,8$, and $9 \mathrm{~mol} \%$ in the six layers from the depth to the surface, respectively. Then the surface of the film was coated onto a 1- $\mu \mathrm{m}$ photoresist and exposed in two steps to a 325-nm-wavelength He-Co laser, resulting in a 2D holed pattern with a period of $1 \mu \mathrm{m}$ that was further coated with a 0.2- $\mu \mathrm{m}$ chromium film. Further processing of the samples consisted of the removal of the photoresist, vertical dry etching in $\mathrm{CHF}_{3}$, and further etch- ing in a 5\%-diluted HF solution for $25 \mathrm{~s}$ at $25^{\circ} \mathrm{C}$. The result was a cylindrical profile that became a cone profile after the wet etching, with sharp tips and grooves $\sim 1.0 \mu \mathrm{m}$ deep. The researchers reported a maximum transmittance of $95.8 \%$ at a wavelength of $1.85 \mu \mathrm{m}$, giving an estimated $0.7 \%$ reflectance for the cone-shaped microstructure, corresponding to one-fifth of the Fresnel reflection at the flat $\mathrm{SiO}_{2}$ surface.

With this method, the researchers anticipate the fabrication of SWS surfaces with deeper grooves and shorter periods, which will lead to antireflection effects for shorter wavelengths. Precise control of the grating aspect ratio is possible by charging the $\mathrm{F}_{2}$-content profile in the films.

IULIA MuNTELE

\section{Ink-Jet Printing Explored for Fabricating Devices and Materials}

University of Arizona researcher Paul Calvert and his collaborators at Sandia National Laboratories are using ink-jet printing to fabricate various organic or inorganic films for electronic devices and sensors. Some of the results on ionic selfassembly of ink-jet-printed polymer films appear in a recent issue of Polymeric Materials: Science $\mathcal{E}$ Engineering for research done in collaboration with Mousa Ghaemi of Mazandaran University in Iran. A detailed overview of the method by P. Calvert can be found in Chem. Mater. 13 (2001) p. 3299.

Ink-jet printing is a highly developed technique for making images. It is now being explored in the printing of devices, especially where organic and inorganic components are combined. The typical examples include organic light-emitting diodes (OLEDs), biochemical sensors, and electronics on flexible substrates. However, the realization of a complex, multilayered, multimaterial device structure requires solutions to a number of problems related to compatibility and reactivity among the substrate and materials being deposited.

To get higher resolutions, the researchers explored depositing gels by inkjet printing and subsequently treating the gel layers with mineralizing solutions. They used a modified HP Deskjet printer to deposit dilute solutions of polydimethyldiallylammonium chloride and polystyrenesulfonate sequentially onto glass slides. The slides were wet-annealed at $70^{\circ} \mathrm{C}$ over a water reservoir, and the polymers self-assembled into an insoluble layer of gel. The same approach allows for submicrometer $\mathrm{Al}_{2} \mathrm{O}_{3}$ particles to be dispersed into the anionic polymer solution. Overprinting with the cationic polymer forms an alumina film bound by a cation/anion gel. Diepoxide/amine sub- 